\title{
Potential for lung sound monitoring during bronchial provocation testing
}

\author{
Abraham B Bohadana, René Peslin, Hubert Uffholtz, Gabrielle Pauli
}

Institut National de

Recherche et de

Securité (INRS) and

Institut National de la

Santé et de la

Recherche Médicale

(INSERM),

U 420 Nancy, France

A B Bohadana

Institut National de la

Santé et de la

Recherche Médicale

(INSERM),

U 14 Nancy, France

R Peslin

Laboratoire

d'Exploration

Fonctionnelle

Pulmonaire, Centre

Hospitalier

Universitaire,

Nancy-Brabois,

France

H Uffholtz

Service de

Pneumologie, Hôpital

Civil de Strasbourg,

Strasbourg, France

G Pauli

Reprint requests to:

Dr A B Bohadana,

Institut National de

Recherche et de Securité

(INRS),

Service d'Epidémiologie,

Av. de Bourgogne

Av. de Bourgogn

Vandoeuvre-lès-Nancy,

France

Received 6 September 1994

Returned to authors

11 January 1995

Revised version received

3 February 1995

Accepted for publication

6 June 1995

\begin{abstract}
Background - The use of lung sound monitoring during bronchial provocation testing has not been clearly demonstrated. The appearance of wheeze and changes in inspiratory breath sound intensity have been analysed and related to changes in spirometric parameters and to airways hyperresponsiveness.

Methods - Lung sounds were recorded in 38 patients undergoing a routine carbachol airway challenge (CAC) test. Spirometric testing was performed before and after the inhalation of each of five cumulative doses of $320 \mu \mathrm{g}$ carbachol; a fall in forced expiratory volume in one second $\left(F_{E V}\right)$ by $20 \%$ or more was considered as significant. Lung sound analysis was carried out using a computerised system.
\end{abstract}

Results - The CAC test was positive $(C A C+)$ in 21 patients and negative $(C A C-)$ in 17 . At the final stage of the challenge, wheeze was identified in 10 positive patients $(48 \%)$ and in one negative patient (6\%); in non-wheezers the inspiratory breath sound intensity decreased significantly from baseline in $11 \mathrm{CAC}+$ patients (mean (SD) change $-35(24 \%)$ ) but not in 16 CAC - patients (mean (SD) change $5(24 \%)$ ). In all non-wheezers a linear relationship was found between breath sound intensity and the squared inspiratory airflow $(r=0.53-0.92)$ which became looser after the inhalation of carbachol.

Conclusion - When undertaking bronchial provocation testing the accurate identification of wheeze may prove useful in avoiding or shortening the test because of the presumed relationship between wheeze and airways hyperresponsiveness. Changes in breath sound intensity may also be useful, but further studies are required to define the threshold for significant changes in this index.

(Thorax 1995;50:955-961)

Keywords: wheeze, breath sound intensity, lung sounds, carbachol airway challenge, airways responsiveness.

Non-specific bronchial responsiveness is a term used to describe the tendency of the airways to constrict upon exposure to non-allergic stimuli such as chemical mediators or physical stimuli. ${ }^{1}$ In the laboratory, bronchial responsiveness can be measured using inhalation provocation tests with either histamine or a cholinergic analogue such as methacholine. ${ }^{2}$ The bronchial response is usually assessed in terms of the provocative dose of the bronchoconstrictor agent leading to a $20 \%$ fall in the forced expiratory volume in one second $\left(\mathrm{FEV}_{1}\right) \cdot{ }^{34}$ Obviously, the use of this technique is limited to subjects capable of performing technically acceptable forced expiratory manoeuvres.

It is a common clinical experience that lung sounds are generally abnormal in acute asthma. In mild disease expiratory wheezes may be heard over central airways. As the asthma becomes more severe, biphasic wheezes of varying pitch may be present all over the chest and, on occasion, they may be heard without the aid of a stethoscope. If asthma is severe wheezes may disappear and the chest may become silent, presumably because airflow is so markedly decreased that no energy is available for sound generation. These observations form the rationale for the many studies carried out over the past decade to examine the relationship between lung sounds and indices of airways obstruction in asthma or bronchial provocation testing. The main interest has been focused on wheezing sounds and on spectrum-describing parameters of breath sounds. ${ }^{5-16}$ Despite some promising results, ${ }^{5791213}$ no consistent quantitative data have been presented for individual patients, so no one acoustic index can be considered to reflect accurately the severity of airways obstruction.

Although disappointing, the reported loose relationship between acoustic and spirometric parameters could merely indicate that lung sounds supply information about the functional status of the airways whose nature is different from that supplied by spirometry. If this reasoning is correct, lung sound monitoring during inhalation provocation tests may provide information about airways responsiveness not available from spirometry. To test this hypothesis we used a computerised system to monitor lung sounds in unselected patients undergoing routine inhalation provocation testing. Our attention was focused on two acoustic phenomena: the appearance of wheeze, which is the most specific clinical sign of airways obstruction, , $^{6-1113-1517}$ and changes in inspiratory breath (vesicular) sound intensity, an index likely to be noticeably decreased in pharmacologically induced airways obstruction. ${ }^{10}$

\section{Methods}

PATIENTS

We evaluated 38 patients undergoing routine carbachol airway challenge (CAC) tests at the pulmonary function laboratory of the Centre Hospitalier Universitaire de Nancy-Brabois, France. They were referred for inhalation provocation testing as part of an investigation of 
Table 1 Mean (SD) anthropometric characteristics, smoking habits, and baseline pulmonary function data of patients $(n=38)$ undergoing routine carbachol airway challenge (CAC) test

\begin{tabular}{ll}
\hline M:F & $12: 26$ \\
Age (years) & $36.5(11.9)$ \\
Height (cm) & $165.5(7 \cdot 9)$ \\
Weight (kg) & $65.3(13 \cdot 6)$ \\
& \\
Smoking habits: & 27 \\
$\quad$ Non-smokers & $7(11(9.5)$ pack years) \\
Smokers & $4(15(10)$ pack years) \\
Ex-smokers & \\
Baseline pulmonary function tests* & \\
FEV & $-0.83(0 \cdot 9)$ \\
FVC & $-0.59(1 \cdot 0)$ \\
Vmax $_{50}$ & $-0.99(0 \cdot 7)$ \\
\hline
\end{tabular}

$\mathrm{FEV}_{1}=$ forced expiratory volume in one second; $\mathrm{FVC}=$ forced vital capacity; $\operatorname{Vmax}_{50}=$ maximal expiratory flow at $50 \%$ of the FVC.

${ }^{*}$ Expressed as standardised residuals (StR). ${ }^{18}$

dyspnoea $(n=3)$, cough $(n=7)$, urticaria $(n=$ $7)$, bronchial asthma $(n=8)$, or chronic rhinitis associated or not with nasal polyposis $(n=$ 13). They were asked to stop theophylline and anticholinergics for 48 hours and $\beta_{2}$ agonists for 12 hours before the study. No patients were receiving regular treatment with inhaled steroids or disodium cromoglycate. Their anthropometric characteristics, smoking habits, and pretest lung function parameters are shown in table 1.

PULMONARY FUNCTION TESTS

Spirometric tests were performed using an electronic spirometer (Auto Spiro AS 500 Minato Medical Science Co Ltd, Osaka, Japan). Forced vital capacity (FVC), forced expiratory volume in one second $\left(\mathrm{FEV}_{1}\right)$, and maximal expiratory flows at various lung volumes (Vmax) were obtained by asking the subject to expire forcefully after a maximal inspiratory manoeuvre. At baseline at least three reproducible (within $5 \%$ for FVC and $\mathrm{FEV}_{1}$ ) forced vital capacity manoeuvres were performed. The largest FVC, $\operatorname{Vmax}_{50}$ and $\mathrm{FEV}_{1}$ values were retained for analysis. Results were expressed as standardised residuals (StR) ( $\mathrm{StR}=$ observed value-predicted value/residual standard deviation) as recommended by the ad hoc committee of the European Respiratory Society. ${ }^{18} \mathrm{~A}$ standardised residual of zero indicates that the observed value is equal to the reference value - that is, at the 50 th percentile; standardised residuals of -1.64 or 1.96 indicate that the results are at the 5th percentile and at the $97 \cdot 5$ th percentile, respectively.

\section{AIRWAYS RESPONSIVENESS}

Carbachol airway challenge (CAC) test was performed according to a protocol used routinely in the pulmonary function laboratory of the Centre Hospitalier Universitaire of Nancy-Brabois. Five cumulative doses of $320 \mu \mathrm{g}$ carbachol were administered in succession using an FDC 88 dosimeter (Mediprom 75014, Paris, France) delivering fixed doses of $80 \mu \mathrm{g}$ carbachol per breath. A nose clip was worn and the aerosol inhaled through the mouth by slow inspiratory capacity manoeuvres each separated by a five second breath hold. One minute after the inhalation of carbachol, lung sound recording (see below) and spirometric tests were performed in that order. The sequence - carbachol inhalation, sound recording and spirometry - lasted 2-3 minutes and was repeated until the fifth dose of carbachol (cumulative dose $1600 \mu \mathrm{g}$ ) was inhaled or when $\mathrm{FEV}_{1}$ fell by $20 \%$ or more from the baseline value $\left(\mathrm{PD}_{20}\right)$. In patients in whom the test was positive the challenge was terminated by the inhalation of two puffs $(200 \mu \mathrm{g})$ of salbutamol.

Patients whose $\mathrm{FEV}_{1}$ fell by $20 \%$ or more were labelled CAC + whereas those whose $\mathrm{FEV}_{1}$ fell by less than $20 \%$ were labelled $\mathrm{CAC}-$. The $\mathrm{PD}_{20}$ in $\mu \mathrm{g}$ carbachol was calculated for each patient by plotting the percentage fall in $\mathrm{FEV}_{1}$ against the dose of carbachol on a log scale and by interpolating the last two points. ${ }^{16}$

\section{SOUND AND AIRFLOW RECORDINGS}

Lung sounds were recorded before and after each aerosol using a system described previously. ${ }^{11}$ Sound was picked up by an electronic stethoscope (Andries-Tek, Austin, Texas, USA) placed at the right posterior lung base, $5 \mathrm{~cm}$ below the angle of the scapula. Patients were instructed to perform inspirations from functional residual capacity (FRC) as fast and deep as necessary to produce a clearly audible breath sound and to expire passively, as uniformly as possible; however, the respiratory frequency was chosen freely by all subjects. Slight pressure was exerted on the head of the stethoscope in order to leave a mark over the chest which allowed successive recordings to be performed at exactly the same site. The audio signal was heard by auscultation and stored simultaneously on magnetic tape using a three channel tape recorder (Nagra IV-SJ, Kudelski, Switzerland) at a recording speed of $9.525 \mathrm{~cm} / \mathrm{s}$. Before recording the audio signal went through two stages of amplification using both the amplifier of the stethoscope and the amplifier incorporated into the tape recorder. The gains of both amplifiers were determined empirically before the study and remained fixed throughout the experiments: the gain of the stethoscope amplifier was at the maximal position whereas the gain of the recorder amplifier was at position 01 .

Airflow at the mouth was measured simultaneously using a 47304 Hewlett Packard flow measuring system equipped with a no. 3 Fleisch pneumotachograph and stored in the FM track (no. 3) of the tape recorder. This system is linear for flows up to $10 \mathrm{l} / \mathrm{s}$, a threshold far beyond the expected values during deep inspiratory manoeuvres.

\section{DATA ANALYSIS}

The recorded sounds were played back in the sequence in which they were recorded, listened to cycle by cycle through earphones, and displayed simultaneously with the corresponding 
flow signal on an oscilloscope (BBC Goerz Metrawatt) for quality control. Material free from voice, movement, or ambient noise artefact was selected for analysis. The amplified audio signal was bandpass filtered between 50 and $2000 \mathrm{~Hz}$, whereas the flow signal was low pass filtered at $20 \mathrm{~Hz}$ (Multimetrics Model AF 220 Active Filter). Data acquisition, analysis, and display were performed using a customised computer program developed for the purpose of this study. Because wheezes are musical sounds whereas breath (vesicular) sounds are not, their analysis was carried out separately as follows:

\section{Step I: screening for wheeze}

All sound recordings were first screened for wheeze. In our experience ${ }^{11}$ and that of others, ${ }^{791314}$ this adventitious musical sound tends to be limited to a maximum frequency of $2000 \mathrm{~Hz}$ or lower. Thus, to cover its frequency range and allow a good spectral band width the audio signal was digitised ( 12 bit $\mathrm{AD}$ converter) at a sampling rate of $4096 \mathrm{~Hz}$ and fed into a microcomputer (Kenitec 486-DX 33). A sound segment of 18 seconds duration (73 728 data points) was saved in the computer memory, from which the first three respiratory cycles were drawn and stored in the computer's hard disk for analysis. Thus, the duration of the sound segment selected for analysis varied ac-

A

\section{Sound}

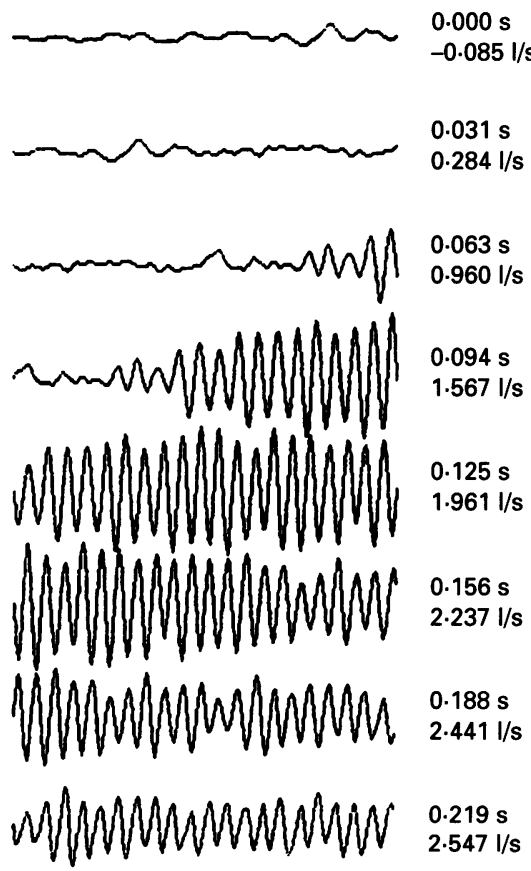

$20 \mathrm{~ms}$

$.000 \mathrm{~s}$

$0.284 \mathrm{l} / \mathrm{s}$

$0.063 \mathrm{~s}$

$0.094 \mathrm{~s}$

$1.567 \mathrm{l} / \mathrm{s}$

$0.125 \mathrm{~s}$

$1.961 \mathrm{l} / \mathrm{s}$

$0.156 \mathrm{~s}$

$2.237 \mathrm{l} / \mathrm{s}$

$0.188 \mathrm{~s}$

$.441 \mathrm{l} / \mathrm{s}$

$2.547 \mathrm{l} / \mathrm{s}$
(Time-expanded)

B

Frequency spectrum

$-0.085 \mathrm{l} / \mathrm{s}$
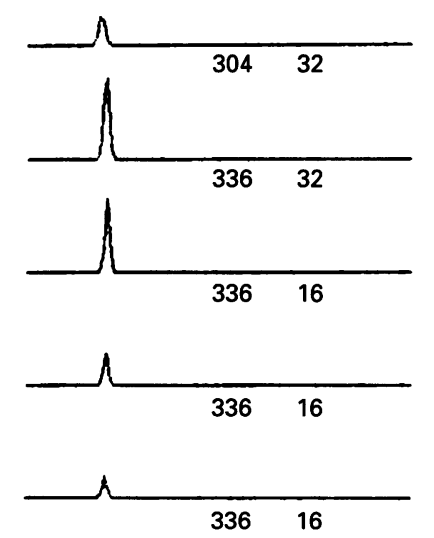

$64 \mathrm{~Hz}$ $1680 \mathrm{~Hz}$

Figure 1 Screening for wheeze (hardcopy of the computer screen). (A) Overlapping $62.5 \mathrm{~ms}$ epochs of time expanded sound waves with $(B)$ the corresponding frequency spectra. The figures in the middle indicate, for each epoch, the time (relative to the beginning of the record) and the mean flow. The latter is inspiratory, starting from the second epoch. The spectra show a single peak, with a much larger amplitude than the background noise; the frequency of the peak and its width at half amplitude are indicated. cording to the respiratory rate. The corresponding flow signal was digitised at $4096 \mathrm{~Hz}$ and stored together with the audio signal, thus allowing the determination of the inspiratory and expiratory portions of the respiratory cycle.

The audio signal was submitted to time expanded wave form analysis and its frequency content was assessed by Fourier analysis. For this the audio signal was divided into short segments or data blocks with $50 \%$ overlapping between successive blocks. The data blocks were visualised on the computer screen along with the corresponding frequency spectrum. An example is shown in fig 1 . Two options were available: blocks of 256 points $(0.0625 \mathrm{~s})$ which offered the best time resolution and a frequency resolution of $16 \mathrm{~Hz}(1 / 0.0625)$, and blocks of 512 points $(0 \cdot 125 \mathrm{~s})$ which offered the best frequency resolution $(8 \mathrm{~Hz})$. Before Fourier analysis a Hanning window was applied to the data blocks to avoid aliasing. A wheeze was considered to be present when regular, sinusoidal-like oscillations were observed in the time expanded wave form analysis ${ }^{17}$ which corresponded to discrete narrow peak (or peaks) of power in the spectral analysis. Moreover, the following peak characteristics were required $^{19}$ : (1) the peak had to be distinctly separate from its surrounding sound spectrum; (2) the peak amplitude had to be at least three times larger than the base it arose from; and (3) the width at half amplitude of the peak should not exceed three times the resolution of the measuring system (either 24 or $48 \mathrm{~Hz}$ for our system).

Step II: evaluation of inspiratory breath sound intensity

Sound recordings of non-wheezers were reexamined for changes in inspiratory breath sound intensity. Wheezers were excluded from this analysis for two reasons: (1) since we were looking for signs of bronchoconstriction, and since wheeze is the most specific sign of this condition, evaluation of breath sound intensity in wheezers would be redundant for this purpose; (2) although wheezes are easy to detect by computer analysis, they can hardly be extracted from the background breath sounds on which they are superimposed.

Each tape was replayed and the amplified audio signal was bandpass filtered between 50 and $700 \mathrm{~Hz}$ whereas the flow signal was low pass filtered at $20 \mathrm{~Hz}$ (Multimetrics Model AF 220 Active Filter). Both signals were then digitised at a sampling rate of $1536 \mathrm{~Hz}$ into the microcomputer. This sampling rate was chosen because we had found in preliminary experiments that inspiratory breath sounds in non-wheezing subjects contained no detectable acoustic energy above $500 \mathrm{~Hz}$. A sound segment of 18 seconds duration (27 648 data points) was momentarily saved in the computer memory, from which the first three respiratory cycles were drawn and stored in the computer's hard disk for analysis. Since breath sound occurring during a quiet, passive expiration is too weak and contains almost no sound energy, analysis was restricted to inspiration. 


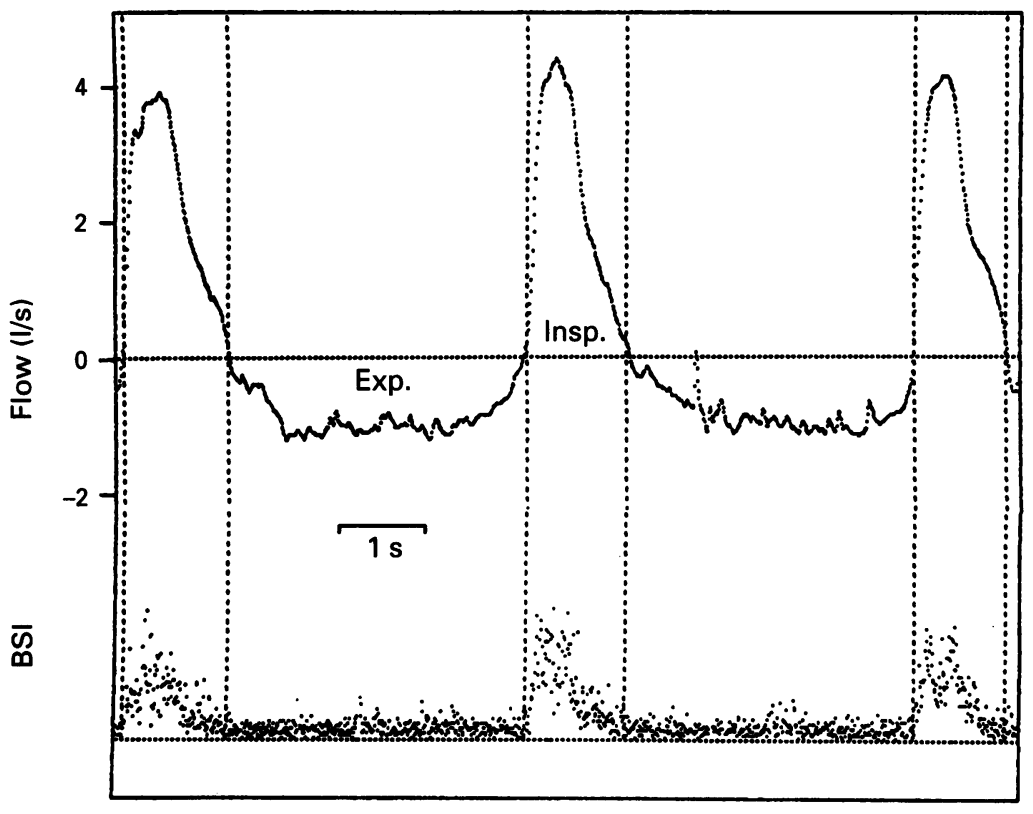

Figure 2 Airflow at the mouth (upper) and corresponding BSI signal in arbitrary units (lower) at baseline in a patient free from wheeze (hard copy from the computer screen).

Breath sound intensity was calculated in terms of RMS sound amplitude on successive data blocks of 32 points ( $1 / 48 \mathrm{~s})$; the flow signal was averaged over the same periods. Since the sound amplitude is highly flow-dependent, several ventilatory parameters were calculated from the flow signal: (a) inspiratory time (Ti) in seconds; (b) tidal volume (VT) in litres; (c) ratio of tidal volume over inspiratory time $(\mathrm{VT} /$ $\mathrm{Ti})$; and (d) the slope and the correlation coefficient $(r)$ of the relationship between the RMS sound amplitude and the corresponding squared inspiratory flow obtained by linear regression analysis; this relationship was examined because a linear correlation between these two variables has been reported in healthy humans. ${ }^{20}$ Airflow and breath sound intensity signals in a patient free from wheeze are shown in fig 2 .

In a preliminary study the variability (dispersion of successive measurements) and the short term reproducibility (difference at a certain time interval) of sound amplitude parameters were determined in five healthy volunteers from the laboratory by repeating the measurements 10 minutes apart. For each acoustic index intrasubject variability was assessed calculating the standard deviation (SD) of the data obtained on three successive respiratory cycles and their mean coefficient of variation $(\mathrm{CV} \%=[\mathrm{SD} / x] \times 100)$. Short term reproducibility was assessed by taking the unsigned difference $(\Delta \mathrm{m} \%)$ between the mean value of the first $(\mathrm{m} 1)$ and second $(\mathrm{m} 2)$ examinations expressed as a percentage of their average: $\Delta \mathrm{m} \%=2 \times[\mathrm{m} 1-\mathrm{m} 2] \times 100$ $[\mathrm{m} 1+\mathrm{m} 2]$.

\section{STATISTICAL ANALYSIS}

Standard statistical analysis was by means of the Mann-Whitney U test and Wilcoxon signed rank sum test as appropriate. For all analyses the SAS statistical pack was used.

\section{Results}

Of 38 patients, $21(55.3 \%)$ had a positive CAC test $(\mathrm{CAC}+)$ and 17 had a negative test $(\mathrm{CAC}-)$. Of the $21 \mathrm{CAC}+$ patients seven had asthma, eight had rhinitis and/or nasal polyposis, three were investigated for cough, two for dyspnoea, and one had urticaria.

At baseline wheeze was identified in five patients. In two wheeze was inspiratory only, in one expiratory, and in two biphasic. The $\mathrm{FEV}_{1}$ of the wheezers was not significantly different from that of the non-wheezers (mean (SD) $-0.83(0.98)$ standardised residuals versus $-0.82(0.97)$ respectively, $p=0.4)$. An example of inspiratory wheeze is shown in fig 1. At the end of the challenge these sounds were identified in 11 subjects (inspiratory in four, expiratory in four, and biphasic in the remaining three). Finally, in the post-bronchodilator step of the challenge wheezes were still present in six patients (inspiratory in three and expiratory in three).

Wheezes are identified at $\mathrm{PD}_{20}$ in 10 of the $21 \mathrm{CAC}+$ patients $(47 \cdot 6 \%)$. In three the dose of carbachol at which the wheeze appeared (PDw) coincided with $\mathrm{PD}_{20}$; in two wheeze was identified respectively one and three steps before reaching $\mathrm{PD}_{20}$ so that $\mathrm{PDw}<\mathrm{PD}_{20}$; in the remaining five wheeze was present already at baseline and persisted throughout the test even after the inhalation of salbutamol. Wheeze was also identified after all aerosols of carbachol in one of the $17 \mathrm{CAC}$ - patients $(5 \cdot 9 \%)$. Thus, at the final step of the challenge wheezes were $48 \%$ sensitive and $94 \%$ specific to detect a drop in $\mathrm{FEV}_{1}$ by $20 \%$ or more.

In the $21 \mathrm{CAC}+$ patients the presence of wheeze correlated well with the severity of the spirometric response to carbachol: in wheezers $(n=10)$ the mean (SD) percentage fall in $\mathrm{FEV}_{1}$

Table 2 Mean (SD) intrasubject variability and short term reproducibility of acoustic parameters in five healthy men of mean (SD) age 41 (7) years, height $176(7 \cdot 2) \mathrm{cm}$, weight $74(8.4) \mathrm{kg}$

\begin{tabular}{|c|c|c|c|c|c|}
\hline Index & Session 1 & $\mathrm{CV}^{\circ} \%$ & Session 2 & $\mathrm{CV}^{\circ} \%$ & $\Delta m \%$ \\
\hline $\begin{array}{l}\text { Ti(s) } \\
\text { VT(I) } \\
\text { VT/Ti(1/s) } \\
\text { BSI } \\
\text { Slope } \\
r \\
\text { (range) }\end{array}$ & $\begin{array}{c}0.86(0.17) \\
2.88(0.56) \\
3.37(0.32) \\
14.2(9.94) \\
0.58(0.39) \\
0.86 \\
(0.83-0.88)\end{array}$ & $\begin{array}{l}5(2) \\
7(5) \\
4(2) \\
9(3) \\
* \\
*\end{array}$ & $\begin{array}{c}0.84(0.19) \\
2.94(0.49) \\
3.58(0.47) \\
12.7(6.8) \\
0.45(0.22) \\
0.85 \\
(0.72-0.90)\end{array}$ & $\begin{array}{r}6(2) \\
3(2) \\
6(2) \\
11(5) \\
*\end{array}$ & $\begin{array}{c}14(7) \\
15(14) \\
8(5 \cdot 1) \\
30(8 \cdot 8) \\
31(28) \\
7(4)\end{array}$ \\
\hline
\end{tabular}

$C V \%=$ coeffient of variation between cycles; $\Delta \mathrm{m} \%=$ average value at session 1 -average value at session $2 /$ average value at $\mathrm{CV} \%=$ coefficient of variation between cycles; $\Delta \mathrm{m} \%=$ average value at session 1 - average value at session $2 /$ ave session $1 \times 100 ; \mathrm{Ti}=$ inspiratory time; $\mathrm{VT}=$ tidal volume; $\mathrm{VT} / \mathrm{Ti}=$ mean inspiratory flow; $\mathrm{BSI}=$ inspiratory root mean amplitude in arbitrary units; slope = slope of the BSI $\mathrm{V}^{2}$ relationship; $r=$ correlation coefficient of that relationship. * Only average values of three cycles are available for each subject at each session so that no individual coefficient of variation can be calculated. 
Table 3 Mean (SD) response of ventilatory and acoustic variables to carbachol and to salbutamol aerosol (200 $\mu \mathrm{g})$ in non-wheezing patients with carbachol challenge test negative $(C A C-)$ or positive $(C A C+)$ by spirometry

\begin{tabular}{|c|c|c|c|c|c|}
\hline & \multicolumn{2}{|l|}{ Baseline } & \multicolumn{2}{|c|}{ After carbachol } & \multirow{2}{*}{$\begin{array}{l}\text { After salbutamol } \\
C A C+ \\
(n=11)\end{array}$} \\
\hline & $\begin{array}{l}C A C- \\
(n=16)\end{array}$ & $\begin{array}{l}C A C+ \\
(n=11)\end{array}$ & $\begin{array}{l}C A C_{-} \\
(n=16)\end{array}$ & $\begin{array}{l}C A C+ \\
(n=11)\end{array}$ & \\
\hline $\begin{array}{l}\mathrm{FEV}_{1}(\mathrm{l}) \\
\quad(\mathrm{StR}(\mathrm{SD}))\end{array}$ & $\begin{array}{l}2.9(0.6) \\
(-0.74(0.9))\end{array}$ & $\begin{array}{l}2 \cdot 6(0.5) \\
(-0.97(0.89))\end{array}$ & $2 \cdot 7(0 \cdot 6)$ & $2 \cdot 0(0 \cdot 3)$ & $2.5(0.5)$ \\
\hline $\mathrm{Ti}(\mathbf{s})$ & $0.76(0.2)$ & $0.86(0.2)$ & $0.77(0.2)$ & $1.01(0.3)^{*}$ & $0.99(0.2)$ \\
\hline $\mathrm{VT}(\mathrm{l})$ & $1.94(0.7)$ & $2.06(0.6)$ & $2.07(0.6)$ & $1.92(0.5)$ & $2 \cdot 17(0 \cdot 6)$ \\
\hline $\mathrm{VT} / \mathrm{Ti}(1 / \mathrm{s})$ & $2.63(0.9)$ & $2 \cdot 44(0 \cdot 7)$ & $2.78(0.9)$ & $2.08(1.0)^{*}$ & $2 \cdot 45(1 \cdot 2)$ \\
\hline BSI & $45 \cdot 0(14 \cdot 6)$ & $40.0(13.0)$ & $46 \cdot 4(15 \cdot 1)$ & $24 \cdot 7(10 \cdot 7)^{* *}$ & $37 \cdot 4(14)$ \\
\hline Slope & $2 \cdot 83(1 \cdot 8)$ & $3.29(2 \cdot 0)$ & $2 \cdot 20(1 \cdot 2)$ & $2.64(3.0)^{*}$ & $3.65(3.0)$ \\
\hline$r$ & $0.73(0.10)$ & $0.78(0.09)$ & $0.70(0.11)$ & $0.60(0.21)^{* *}$ & $0.70(0.08)$ \\
\hline
\end{tabular}

$\mathrm{FEV}_{1}=$ forced expiratory volume in one second; $\mathrm{StR}=$ standardised residuals; $\mathrm{Ti}$ =inspiratory time; $\mathrm{VT}=$ tidal volume; VT/Ti= mean inspiratory flow; BSI = inspiratory root mean square sound amplitude in arbitrary units; slope $=$ slope of the $\mathrm{BSI} / \mathrm{V}^{2}$ mean inspiratory flow; $\mathrm{BSI}=$ inspiratory root mean square sound amplitude in arbitrary units; slope $=$ slope of the BSI
relationship; $r=$ correlation coefficient of that relationship. Comparisons between $\mathrm{CAC}-$ and $\mathrm{CAC}+$ at baseline showed no relationship; $r=$ correlation coefficient of that relationsh
significant differences whatever the index considered.

${ }^{*} \mathrm{p}<0.05 ;{ }^{* *} \mathrm{p}<0.01$ for comparisons between variables of $\mathrm{CAC}+$ patients at end of challenge versus baseline.

at $\mathrm{PD}_{20}$ was 38 (14) (range 20-62) compared with 24 (3) (range 21-30) for non-wheezers $(n=11)(p<0 \cdot 05)$. Conversely, for wheezers the mean $\mathrm{PD}_{20}$ value in $\mu \mathrm{g}$ carbachol was 279 (455) (range 22-1412) compared with 934 (427) (range 398-1513) for non-wheezers.

The normal variability and reproducibility of the various acoustic and ventilatory variables were within acceptable limits and are shown in table 2 . The mean CV\% ranged from $3 \%$, seen for VT in session 2, to $11 \%$, observed for breath sound intensity in session 2 ; for $\Delta \mathrm{m} \%$ the lowest and highest values were, respectively, $7 \%$ for the correlation coefficient of the breath sound intensity/squared flow relationship and $31 \%$ for the slope of this relationship.

At $\mathrm{PD}_{20}$, the inspiratory breath sound intensity decreased noticeably from baseline in $\mathrm{CAC}+$ non-wheezers but not in CAC - nonwheezers; the mean (SD) individual variation in breath sound intensity expressed as a percentage of the initial value for the two subgroups was $-35(24) \%$ and $5(24) \%$, respectively $(\mathrm{p}<0.001)$.

The absolute values of breath sound intensity and other acoustic and ventilatory variables observed at each step of the challenge are shown separately for the two subgroups of non-wheezers in table 3. The main differences between these two subgroups can be summarised as follows: (a) in CAC + patients inspiratory time increased significantly after the inhalation of carbachol but did not return towards baseline after the inhalation of salbutamol; (b) in CAC + patients both breath sound intensity and inspiratory flow (VT/Ti) decreased significantly after the inhalation of carbachol and increased back towards baseline values after the inhalation of salbutamol; (c) in both subgroups a positive linear relationship was found between breath sound intensity and the corresponding squared inspiratory airflow with correlation coefficients $(r)$ at baseline ranging from 0.53 to 0.92 , and (d) in CAC+ patients both the slope and the coefficient of correlation of the breath sound intensity/ squared flow curve decreased significantly at $\mathrm{PD}_{20}$.

\section{Discussion}

This study identified wheeze in $48 \%$ of those subjects with a positive carbachol challenge test and in the remainder the breath sound intensity fell markedly, whereas in those with a negative challenge test only one subject $(6 \%)$ wheezed and in the remainder breath sound intensity was essentially unchanged. These results suggest a possible role for lung sound monitoring in the context of tests for bronchial hyperresponsiveness.

Wheeze is an adventitious musical sound usually associated with obstructive disorders of the airways. The results of this study confirm our previous observations ${ }^{11}$ and those of others ${ }^{8914}$ that this sign is a poorly sensitive but highly specific detector of airways obstruction. This finding is in keeping with the mechanism of wheeze generation as proposed by Grotberg and Davis ${ }^{21}$ and by Gavriely and coworkers. ${ }^{22-25}$ According to these authors, wheeze would result from the coupled oscillation of the airway gas and the airway wall in partially collapsed central airways which occurs when airflow velocity increases above a critical threshold, and the pleural pressure reaches a critical value greater than that required for airways limitation. Since wheeze generation requires airways limitation at a local level, this sign can, but does not necessarily have to be, related to $\mathrm{FEV}_{1}$, an index expressing overall airways limitation. Conversely, overall airways obstruction may coexist with an absence of wheeze.

A clinically useful approach is to analyse the appearance of wheeze during airway inhalation tests in the light of its presumed relationship with airways hyperresponsiveness. Holgate and coworkers $^{26}$ have stressed that, from a symptomatic point of view, airways hyperresponsiveness is related to bronchial irritability (which presents as attacks of wheezing, chest tightness, or shortness of breath upon exposure to various stimuli ${ }^{27}$ ), and that "bronchial hyperresponsiveness and irritability are intimately associated with paroxysms of bronchospasm that characterise asthma and comprise a major part of its clinical definition". ${ }^{28}$ It therefore seems reasonable to consider that wheeze triggered by non-specific stimuli is in itself a manifestation of airways hyperresponsiveness, a concept that seems to be shared by others. ${ }^{81329}$

The adoption of the above concept in pulmonary function testing would have had several practical consequences for our patients. Firstly, smaller doses of carbachol would have been 
A

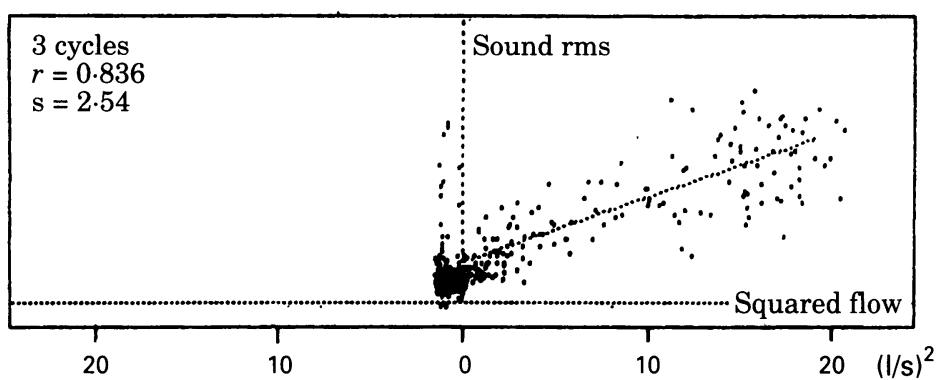

B

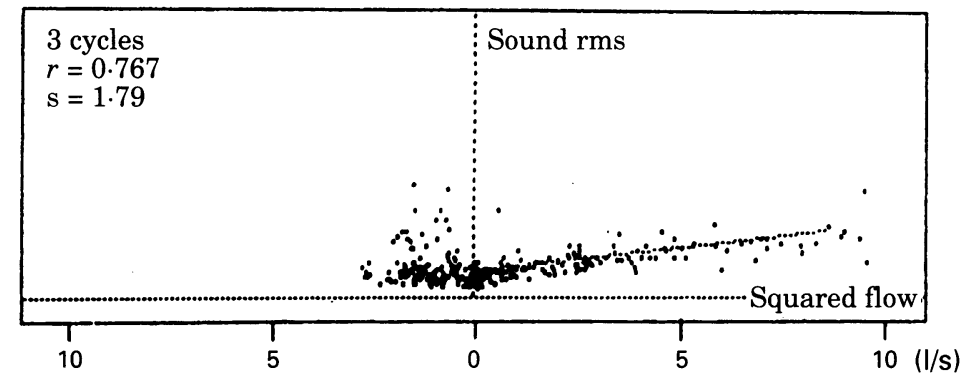

$\mathrm{C}$

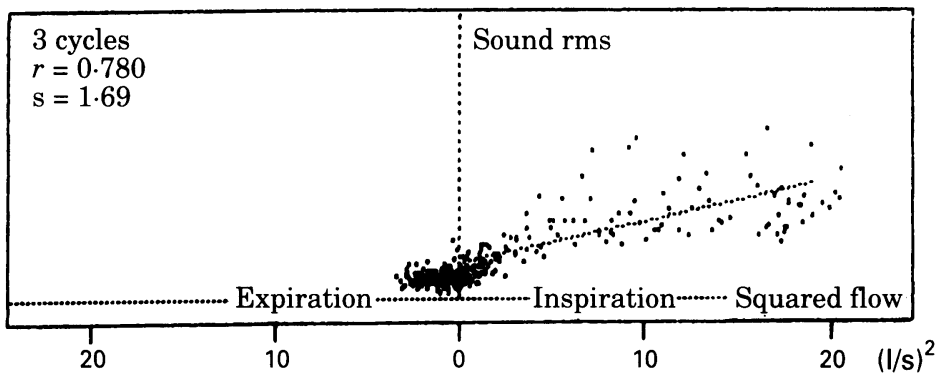

Figure $3 B S I / \dot{V}^{2}$ relationship in a non-wheezer $C A C+$ (hardcopy from the computer screen). Recordings done at $(A)$ baseline, $(B)$ end of challenge, and $(C)$ after salbutamol. Changes in the slope ( $s$, in arbitrary units) and in the correlation coefficient (r) of the BSI/ $\dot{V}^{2}$ relationship are observed. Differences in the full scale of squared flow in (B) compared with $(A)$ and $(C)$ should be taken into account when analysing slope changes. obstruction, and confirmed subsequently by several authors. ${ }^{31-35}$ Based upon these studies and on our own experience we reasoned that, if the above relationship holds also in acute conditions, a fall in $\mathrm{FEV}_{1}$ by $20 \%$ or more should be accompanied by a noticeable decrease in inspiratory breath sound intensity over the chest, regardless of the presence of wheeze; such an expectation has been somewhat confirmed in a small group of selected patients. ${ }^{10}$

The relationship between inspiratory breath sound intensity and airway patency is complex, especially because the mechanism and site of sound production are not entirely known. ${ }^{36}$ Shykoff and colleague ${ }^{20}$ observed recently that, in intact men, the inspiratory breath sound intensity was highly correlated with the square of the simultaneous flow at the mouth, and suggested that inspiratory breath sound could be generated by pressure fluctuations in the airway bifurcations. In this study we observed a similar significant linear correlation between breath sound intensity and squared flow in all patients tested. However, at $\mathrm{PD}_{20}$ not only the correlation coefficients became looser but the slope of this relationship decreased noticeably in CAC + non-wheezers, a trend which was reverted by the inhalation of salbutamol (table 3, fig 3). This finding supports the view that, in these patients, either the site of sound generation or the sound transmission properties of the lung parenchyma are altered, or both. In fact, had the decrease in RMS observed after carbachol been merely a matter of lower inspiratory flows - as suggested by the observed decrease in VT/Ti (table 3) - no significant changes would be expected to occur in the slope of the breath sound intensity/squared flow relationship.

The changes in breath sound intensity reported herein are at variance with two previous reports. In one, Tinkelman and colleagues ${ }^{37}$ claimed breath sound intensity to significantly increase at $\mathrm{PD}_{20}$ during methacholine challenge testing in children between two and six years old. However, in that study the two phases of the respiratory cycle were not examined separately, neither were wheezers separated from non-wheezers. Thus the hypothesis that the low energy breath sound was "contaminated" by the high energy wheezes cannot be ruled out. In the second study, aimed primarily at examining the changes in frequency spectra of breath sounds during histamine challenge testing, Malmberg and coworkers ${ }^{12}$ measured breath sound intensity simultaneously at the trachea and over the chest in 12 adult asthmatic subjects and six healthy controls. In both groups the average inspiratory breath sound intensity over the chest did not change significantly at end of challenge, despite a mean fall in $\mathrm{FEV}_{1}$ of $27 \%$. However, these authors recorded breath sounds at much lower inspiratory flows (target peak flow $1.25 \mathrm{l} / \mathrm{s}$ ) than in our study.

Our observed changes in breath sound intensity could have been influenced by variations in the site of successive recordings, even if they were small. ${ }^{38}$ However, this factor cannot be 
entirely responsible for the trend we observed because, had small variations in the site of recording occurred, the chance would be identical for this to produce either spuriously high or low breath sound intensity values in all subjects and not systematically low values as seen in CAC + patients (table 3). Regarding the variability of our acoustic indices, no similar data are available for comparison. However, compared with indices of lung function, our figures are higher than those seen for $F E V_{1}$ but within the range of those of plethysmographic indices. ${ }^{39}$

In conclusion, this study showed that wheeze identification before and after the inhalation of a cholinergic agent is clinically useful provided the concept is accepted that pharmacologically triggered wheeze is as legitimate a manifestation of airways hyperresponsiveness as is a fall in $\mathrm{FEV}_{1}$. In practice this should prompt the discontinuation of the challenge test or, at least, the lowering of the next dose of the provocative drug. In turn, the presence of wheeze before the challenge can, in the appropriate context, be considered as enough evidence of airway hyperresponsiveness to exempt the patient from the test; if deemed necessary the latter could be carried out employing a low dose protocol as for asthmatics, regardless of the baseline $\mathrm{FEV}_{1}$. Finally, by extension, the monitoring of inspiratory breath sound intensity seems to be potentially useful; however, as this index has a quantitative dimension further research is necessary to define the range of normal variation.

The authors thank Dr S Meghrebi for performing airway provocation challenge, $\mathrm{Mr} S$ Metropolit for the computer program for data acquisition, and Mr P Wild for help with the statistica analysis.

1 Hargreave FE, Dolovich J, O'Byrne PM, Helen Ramsdale E, Daniel EE. The origin of airway hyperresponsiveness. f Allergy Clin Immunol 1986;78:825-32.

2 Juniper EH, Cockroft DW, Hargreave FE. Histamine and methacholine inhalation tests: tidal breathing method. Laboratory procedure and standardization. Canadian Thoracic Society Statement. Lund: AB Draco; 1991.

3 Cropp JA, Bernstein LI, Boushey HA Jr, Hyde RW, Rosenthal RR, Sheldon LS, et al. Guidelines for bronchial inhalation challenges with pharmacologic and antigenic agents. ATS News, Spring 1980; $11-9$.

4 Eiser NM, Kerrebijn KF, Quanjer Ph H. Guidelines fo standardization of bronchial challenges with (nonspecific) bronchoconstricting agents. Bull Eur Physiopathol Respir 1983;19:495-514.

5 Anderson K, Aitken S, Carter R, MacLeod JES, Moran F. Variation of breath sound and airway caliber induced by histamine challenge. Am Rev Respir Dis 1990;141: 1147-50.

6 Avital A, Bar-Ishay E, Springer C, Godfrey S. Bronchial provocation test in young children using tracheal aus provocation test in young children
cultation. $\mathcal{F}$ Pediatr 1989;112:591-4.

7 Baughmann RP, Loudon RG. Quantitation of wheezing in acute asthma. Chest 1984;86:719-22.

8 Baumann UA, Haerdi E, Keller R. Relations between clinical signs and lung function in bronchial asthma: how is acute bronchial obstruction reflected in dyspnoea and wheezing? Respiration 1986;50:294-300.

9 Beck R, Dickson U, Montgomery MD, Mitchell I. Histamine challenge in young children using computerized tamine challenge in young children using co

10 Bohadana AB, Kopferschmitt-Kubler M-C, Pauli G. Breath sound intensity in patients with airway provocation challenge test positive by spirometry but negative for wheezing. a preliminary report. Respiration 1994;61:274-9.
11 Bohadana AB, Massin N, Teculescu D, Peslin R. Tracheal wheezes during methacholine airway challenge (MAC) in workers exposed to occupational hazards. Respir Med 1994;88:581-7.

12 Malmberg LP, Sovijärvi ARA, Paajanen E, Piirilä P, Haahtela $T$, Katila $T$. Changes in frequency spectra of breath sounds during histamine challenge test in adults and healthy control subjects. Chest 1994;105:122-32.

13 Pasterkamp H, Tal A, Leahy F, Fenton R, Chernick V. The effect of anticholinergic treatments on postexertional wheezing in asthma studied by phonopneumography and spirometry. Am Rev Respir Dis 1985;132:16-21.

14 Sanchez I, Avital A, Wong I, Tal A, Pasterkamp H. Acoustic vs spirometric assessment of bronchial responsiveness to methacholine in children. Pediatr Pulmonol 1993;15:28 35.

15 Spence DPS, Bentley S, Evans DH, Morgan MDL. Effect of methacholine induced bronchoconstriction on the spectral characteristics of breath sounds in asthma. Thorax 1992, 47:680-3.

16 Sterk PJ, Fabbri LM, Quanjer Ph H, Cockcroft DW, O'Byrne PM, Anderson SD, et al. Airway responsiveness. Standardized challenge testing with pharmacological physical and sensitizing stimuli in adults. Eur Respir $f$ 1993;6(Suppl 16):53-83.

17 Murphy RLH Jr, Holford SK, Knowler WC. Visual lung sound characterization by time-expanded waveforem analysis. N Engl F Med 1977;296:968-71

18 Quanjer $\mathrm{Ph} \mathrm{H}$, Tammeling GJ, Cotes JE, Pedersen OF, Peslin R, Yernault J-C. Lung volumes and forced respiratory flows. Report working party. Standardization of Lung Function Tests. European Community for Coal and Steel. Eur Respir f 1993;6(Suppl 16):5-40.

19 Beck R, Gavriely N. The reproducibility of forced expiratory wheezes. Am Rev Respir Dis 1990;141:1418-22.

20 Shykoff B, Ploysongsang Y, Chang HK. Airflow and normal lung sounds. Am Rev Respir Dis 1988;137:872-6.

21 Grotberg JB, Davis SH. Fluid dynamic flapping of a collapsible channel: sound generation and flow limitation. $\mathcal{f}$ Biomech 1980;13:219-30.

22 Gavriely N, Kelly KB, Grotberg JB, Loring SH. Forced expiratory wheezes are a manifestation of airway flow limitation. F Appl Physiol 1987;62:2398-403.

23 Gavriely N, Kelly KB, Grotberg JB, Loring SH. Critical pressures required for generation of forced expiratory pressures required for generation of for
wheezes. $\mathcal{F}$ Appl Physiol 1989;66:1136-42.

24 Gavriely N, Palty Y, Alroy G, Grotberg JB. Measuremen and theory of wheezing breath sounds. $\mathcal{f}$ Appl Physiol 1984;57:481-92.

25 Gavriely N, Shee TR, Cugell DW, Grotberg JB. Flutter in flow-limited collapsible tubes - a mechanism for the generation of wheezes. 7 Appl Physiol 1989;66:2251-61.

26 Holgate ST, Beasley R, Twentyman OP. The pathogenesis and significance of bronchial hyperrreponsiveness in airway disease. Clin Sci 1987;73:562-72.

27 Mortagy AK, Howell JBL, Waters WE. Respiratory symptoms and bronchial reactivity identification of a syndrome toms and bronchial reactivity identification of a syndr

28 CIBA Foundation Study Group No 38. The identification of asthma. Edinburgh: Churchill Livingstone, 1971.

29 Nicod L, Pécoud A, Leuenberger P. Specificity and safety of bronchial provocation tests with a purified extract of Dermatophagoides pteronyssinus. Prog Respir Res 1985;19. 266-70.

30 Laënnec RTH. De l'Auscultation Médiate. Paris: Brosson et Chaudé 1819.

31 Badgett RG, Tanaka DJ, Hunt DK, Jelley MJ, Feinberg LE, Steiner JF, et al. Can moderate chronic obstructive pulmonary disease be diagnosed by historical and physical pulmonary disease be diagnosed by historical
findings alone? $A m \mathcal{F}$ Med 1993;94:188-96.

32 Bohadana AB, Peslin R, Uffholz $\mathrm{H}$. Breath sounds in the clinical assessment of airflow obstruction. Thorax 1978 33:345-51.

33 Nairn JR, Turner-Warwick M. Breath sounds in emphysema. Br f Dis Chest 1969;63:29-37.

34 Pardee NE, Martin CJ, Morgan EH. A test of the practical value of estimating breath sound intensity. Breath sound related to measured ventilatory function. Chest 1976;70: $341-4$.

35 Schneider IC, Anderson AE. Correlation of clinical signs with ventilatory function in obstructive lung disease. Ann Intern Med 1965;62:477-85.

36 Kraman S. Vesicular (normal) lung sounds: how are they made, where do they come from, and what do they mean? Semin Respir Med 1985;6:183-91.

37 Tinkelman DG, Lutz C, Conner B. Methacholine challenges in the management of young children. Ann Allergy 1991; 66:225-30.

38 Dosani R, Kraman S. Lung sound intensity variability in normal men. A contour phonopneumographic study. Chest normal men. A contc

39 Teculescu DB, Bohadana AB, Peslin R, Pinot J, Jansen da Silva JM. Variability, reproducibility and observer difference of body plethysmographic measurements. Clin Physiol 1982;2:127-38 